\title{
The Access Model: Managing the Transformation at Aston University Sheila M. Corrall
}

\section{Background - "The Need to Weed" and Other Stories}

The application of the "small is beautiful" principle to academic libraries has been a topic for professional debate over many years. In the UK, the controversial Atkinson report of the mid1970 s introduced the concept of "the self-renewing library" as a potential solution to the problem of financing the inexorable growth in university library collections [1]. The major concern then was an anticipated shortage of capital funds to build new libraries. However, a decade later, evidence suggested that "the need to weed" on a systematic basis had not really been accepted by the community at large; moreover, at least ten new buildings had been funded by the University Grants Committee (UGC) in the interim, and the level of capital investment in automation projects during this period was also significant [2]. The pattern of recurrent funding at this time tells a different story: successive surveys by the Standing Conference of National and University Libraries and the Centre for Library and Information Management show libraries generally receiving a smaller share of institutional funds, experiencing considerable reductions in acquisitions purchasing power (in the face of high inflation in literature costs) and struggling to cope with increased demand for their services [3]. Strategies for dealing with this by now familiar situation have emerged only slowly in the traditional university library sector in the UK, a notable early exponent being the University of Sussex, which adopted a "demand-led" book acquisitions policy in the mid-1980s [4].

In the wider context of the UK library and information sector as a whole, the Library and Information Services Council for England (LISC) issued a series of seminal reports between 1982 and 1986 on the future development of libraries. The second report, Working together within a National Framework [5], represents a landmark as one of the first explicit attempts to articulate a strategy to enable libraries to fulfil their respective roles against a backdrop of severe financial constraints and proliferation of information resources. The report identified three possible approaches:

(1) to spread resources as satisfactorily as possible over the whole range of possible objectives;

(2) to be selective as to the needs which they would aim to satisfy; or

(3) to develop more effective means of drawing on the library and information resources of the country as a whole to supplement, or even replace, their own resources.

The preferred option was clearly stated:

It is in our view desirable that libraries and information services should move more purposefully from a mainly "holdings" strategy requiring the accumulation of large stocks towards a mainly "access" strategy in which emphasis is placed on the efficient procurement of material and information as required... Emphasis needs to be placed on obtaining, from whatever source, quick and accurate answers to today's questions, using printed, electronic or other media or personal contacts as circumstances demand[ 5].

The report noted that this trend was already established in industry. It recognized that the "storehouse of knowledge" role would remain a valid one for libraries with an arts and humanities bias, but urged a reassessment of the balance between the storehouse and "gateway" roles, and suggested that the development of full-text databases and electronic 
document delivery services might change the pattern of demands in more dynamic subject areas, facilitated by the advent of electronic networks. Ten years on these concepts have become part of our everyday professional vocabulary, and we have even coined new expressions to give them a 1990s feel, as we talk about moving from a "just-in-case" to a "justin-time" model (borrowing the terminology of Japanese management). Advances in networking and other new technologies have also encouraged use of terms such as the "library without walls", the "logical library" and the "virtual library", depicting a situation "where the user has the illusion of access to a much larger collection of information than is really present" [6]. Yet the number of UK university libraries that have actually moved significantly in this direction remains relatively few, as far as can be judged by publicized examples. That is not to say that many libraries have not cut back substantially on their holdings of printed materials and increased their reliance on interlibrary loans and/or electronic services; however, in most cases the shift seems to have taken place more at the tactical than at the strategic level, probably because the level of financial investment has so far amounted to only a small proportion of the budget [7]. Aston University Library \& Information Services (LIS) is one of the exceptions, having determined to pursue an "access" strategy as a result of a strategic review conducted during 1985-86.

\section{Aston University}

The University of Aston in Birmingham was established in 1966, as one of a group of technological universities created out of former Colleges of Advanced Technology. In 1981, the institution took a 31 per cent drop in its recurrent grant, which provided the opportunity to redefine its long-term objectives and resulted in a programme of comprehensive restructuring over the rest of the 1980s. The university followed a consistent "quality-driven market-led" strategy through the reshaping of its academic programmes, merger or closure of half of its academic departments, and departure of half of its staff. It subsequently redesigned its library and computing infrastructure, completed a major physical redevelopment plan and has recently recruited new professorial staff to lead a drive to improve its research standing.

Aston's academic strategy is based on a determination to serve the needs of society particularly industry, commerce and the public sector - through a distinctive mix of offerings emphasizing readily applicable knowledge and featuring sandwich programmes, a European dimension and commitment to the use of information technology (IT) across all its activities. The university has nine academic departments organized within three faculties: Engineering and Applied Science; Life and Health Sciences; and Management and Modern Languages. The "technological" orientation is exemplified by its Modern Languages programmes, which concentrate not on literature, but on the socio-economic and political aspects of the relevant country. The current student population is around 4,000, with some expansion planned over the next few years.

During the 1980s, Aston invested substantially in its IT infrastructure. In 1982, an integrated library housekeeping system was implemented and in 1986, central computing facilities were upgraded; then, in 1988, with significant support from the UGC and the Department of Trade and Industry (DTI), a major project began to install a £4 million broadband Open Systems Interconnection (OSI) local area network, spanning the entire campus and providing a total of around 2,500 connection points for both data and video. Project ACCENT was the first demonstrator site under the DTI OSI awareness programme, and an important part of this project was the development and demonstration of networked library services, with a member of LIS staff being seconded to work as a member of the project team. There is now widespread 
use of office automation and electronic mail facilities across the campus. In addition, there are clusters of networked PCs sited in central locations (including the library building) and also in academic departments for students to use a variety of specialist tools, packages and simulations in the learning process, as well as standard word processing, spreadsheets, desktop publishing and database software.

\section{Forward Strategy 1986-90 - The Industrial Information Service}

In 1985, a new Director of Library \& Information Services was appointed and a fundamental review was undertaken to provide a strategic framework for service developments into the 1990s. Key factors influencing the direction taken were the fast pace of change, the institution's commitment to IT, and the orientation of its academic programmes. In common with similar institutions, LIS did not have any significant historical collections, but the subject mix of programmes supported did not point to a need to build collections of the depth and breadth associated with the traditional university library model. LIS already had automated systems in place, and was making extensive use of external bibliographic services.

The model chosen then was that of a modern proactive information service, more akin to the specialist units commonly found in industry and commerce. Its main characteristics, outlined at a conference on The Electronic Campus [8] in 1988, can be summarized as follows:

- Service orientation - actively encouraging full use of LIS; shifting resources into frontline activities; providing visible, tailored services to support particular user groups.

- Collection development - meeting current, immediate needs only of teaching and research; matching resource allocation to identified academic priorities; weeding as well as collecting.

- Cataloguing - serving basic bibliographic needs; purchasing records from external sources; delegating work to paraprofessional/clerical staff.

- Rapid and comprehensive access - providing unrationed document supply services from other sources; monitoring requests to check whether purchases are justified.

- Proactive information services - delivering information skills programmes, mediated online searches, current awareness and support for end-user searching (through a team of information specialists).

- Exploitation of IT - vigorous, cost effective application to all activities.

Between 1986 and 1990, substantial progress was made in moving towards the access model and establishing the service ethos desired. New staffed information points were established to provide one-to-one assistance to users, and a new range of information/instructional leaflets introduced. Opening hours were revised to reflect student demand, including selected Sunday afternoons. All current serials subscriptions were reviewed: changes were made to reflect priorities in research and teaching, a regular review process was established, and an annual respacing and relegation programme was introduced to transfer lower use material to a newly created store. A systematic process for obtaining course information and reading lists from academic staff was established as a fundamental element of acquisitions policy; planned collection development exercises were conducted in specific areas, in conjunction with academics. The interlibrary loans service was automated, with electronic transmission of requests, to cope with a high level of demand. Mediated online searching was actively promoted to departments, with subsidized searches offered to first-year PhD students. Self-service 
electronic information systems were introduced, with information specialists acting as trainers and advisers.

\section{Supporting Strategies}

The basic concept underlying the Aston LIS strategy has been that of a locally-held core collection to meet primary needs, complemented by rapid access to material from external sources, identified through a range of information services and backed up by an effective document supply service. However, the strategy embraces more than this simple statement of the holdings/access balance; a genuine commitment to access requires an open, customeroriented environment, which implies not only pleasant physical surroundings, but also competent and helpful staff.

Aston has accordingly given high priority to both physical improvement and staff development. A phased programme of physical refurbishment transformed the ground and first floors of the library building, by replacing the service counter, providing a new open short loan collection and improved display/viewing areas for current serials, newspapers, microforms and video programmes. An innovative information skills suite was created on the second floor, comprising meeting/seminar rooms and a workshop with sophisticated facilities for demonstrating and teaching search and retrieval techniques. During this period, considerable effort was also put into staff development, including the design of induction programmes for new staff, customer care training for managers and front-line staff, IT training for senior and support staff, professional updating and management skills, with much of this activity being conducted on-site with the university's own specialist trainers. In addition many of the service developments were pursued through project groups, which provided further opportunities for skills development for staff at all levels.

The supporting strategies underpinning the above include (as already indicated) a strong commitment to the exploitation of IT - in library housekeeping, information services, and also in administrative and management tasks through office automation tools[9]. Another distinctive component of the approach adopted at Aston has been a determination to ensure the efficient management of LIS financial and other resources by adopting a professional managerial approach. Again between 1986 and 1990 significant progress was made in this direction: a new system of devolved budgetary control and reporting procedures was introduced, based on monthly in-house spreadsheets of commitments, income and expenditure; a financial model was developed, drawing on both internal and external sources of information, to calculate the rates of inflation for books and serials for the disciplines covered by LIS acquisitions; and, in 1988, a major initiative to develop performance indicators for all areas of service was launched with the appointment of a fulltime member of staff to lead the project.

Finally, an essential factor enabling fulfilment of the objectives set for this period was the full support of the university for the LIS strategy, and the translation of that support into financial resources. Several of the initiatives outlined received special funding (for example, a collection development exercise in the business area was supported by an addition to the LIS recurrent budget; and the information skills suite was partly financed by a UGC award, as well as significant refurbishment funds from the university) and the budget was generally not under too much pressure, with an element of "inflation-proofing" for acquisitions regularly added to the baseline. At the same time, some 10 per cent of LIS posts were shed during this period - but through management choice, and without significant loss of service. 


\section{Strategic Plan 1991-95 - A Self-Service Library}

During 1989-90 a second strategic review was undertaken, and after a highly participative planning exercise, a new strategic plan for LIS was produced to take it forward to the mid1990s. The exercise was used as an opportunity to take stock of progress, to analyse trends and developments in the external environment, and to consult major user groups about their needs and requirements. Key environmental factors were identified in relation to developments in higher education, in publishing and IT, and in library and information services. Important trends emerging from this analysis included the following:

- Expansion in student numbers, and changes in teaching/learning patterns.

- Significant shift towards electronic information and document delivery services.

- Proliferation of electronic products and services, with a wider range of options, (including CD-ROMs, locally and nationally networked services).

- Associated issues of costs, licensing arrangements, copyright and technical problems of networked multi-user access.

- A move towards direct user access to services, including distributed provision to the desktop.

Among the management implications for LIS, the following requirements were identified:

- To analyse expenditure in more detail (in relation to usage) and to review methods of resource allocation.

- To demonstrate value for money in a more competitive bidding situation.

- To acquire more detailed knowledge of different user communities and their academic objectives, in order to tailor services to specific needs.

- To ensure that academic staff and students were aware of developments and equipped with appropriate information handling skills.

- To co-operate closely with other central providers, particularly computing services.

While anticipating a period of continuing turbulence and challenge, no significant change of direction for LIS was envisaged; indeed, the review served to confirm previous planning assumptions and reinforce commitment to the path already chosen. Nevertheless, it had become clear that several factors were critical to the successful fulfilment of the plan: development of the infrastructure provided by the ACCENT network, in view of the anticipated shift from print to electronic sources and the trend towards direct access for users; a high level of skill and adaptability amongst LIS and academic staff and students; continuation of special inflation provision for acquisitions, given the continuing high level of inflation on books and journals, and the expectation that the newer media would not cost less; additional capital provision for the phased replacement of equipment nearing the end of its useful life; and continuing recurrent provision to support the employment of temporary staff to undertake essential annual projects (such as the removal of journals to the remote store). The plan also indicated that additional staff resources in several areas were desirable, notably dedicated technical support for the wide range of equipment used. 


\section{Financial Imperatives}

1991 marked another watershed for LIS, with a change of director, and also the onset of a period of financial constraint, which combined with later changes in funding arrangements within the institution to pose even greater challenges than those originally envisaged. The net result has been a substantial reduction in our recurrent budget, severely limited capital provision (for IT equipment, etc.) and no scope for the creation of new posts - other than in place of equivalent savings elsewhere. Nevertheless, substantial progress in implementing our chosen strategy has been made over the past three years, and the pace of change in terms of the number and nature of new service developments has not slowed at all. Similarly, financial imperatives have concentrated our attention on important management issues, including methodologies for service costings and ongoing arrangements for liaison and consultation with academic departments. In such circumstances, the benefits of a clearly articulated strategy have certainly been demonstrated - the viability of our chosen access model and our ability to manage its implementation are being thoroughly tested.

Three recurring themes characterize service developments in recent years:

(1) Extension of self-service facilities, both within the library building and distributed across the campus network.

(2) Expansion of the range and scope of electronic media available on the campus, including locally networked CD-ROM products as well as nationally networked catalogues and datasets.

(3) Promotion of information management expertise within the Aston community, emphasizing the development of information handling skills in students and staff and the integration of relevant techniques in teaching and research programmes.

With the completion of Project ACCENT in 1992, users now have access to the Online Public Access Catalogue from PCs and Macintoshes in labs and offices throughout the campus; they can look at their own user record, renew or reserve books, send messages to LIS, check and request print-outs of reading lists and receive overdue/recall notices [10]. Similarly, introduction of the Bath Information and Data Services (BIDS) via the Joint Academic Network (JANET) and phased implementation of a local CD-ROM network now offers customers a wide choice of bibliographic, financial and full-text databases from a variety of access points; a booking system is in operation for services offered only within the library building as a means of dealing with heavy demand and giving students the opportunity to plan their work in advance. In support of the above, LIS information specialists run regular and ad hoc sessions to introduce students and staff to the resources available, increasingly timetabled to coincide with particular work assignments but also including more general topics, such as the use of bibliographic management software. A comprehensive range of promotional literature and instructional leaflets has been produced, designed to help users at every stage of the process from getting connected to the campus network to conducting searches of specific databases [11].

\section{Resources and Services}

Collection development during this period has been influenced by the development of the network infrastructure, the availability of new electronic information products and services, and by severe budget pressures over the past two years in particular. As a result of the latter there has been a move away from experimentation with parallel provision of electronic and equivalent hard-copy information resources to straight substitution of electronic for printed sources, 
combined with increasing reliance on interlibrary loan/document supply from remote sources. Previously, it was possible to use earmarked UGC monies for collection development as pumppriming for specific initiatives, including not only the trial of CD-ROM products, but also the BIDS subscription, support for new professorial appointments and purchase of journal back-runs. Now, the depletion of reserves together with the reduction in recurrent funding (including withdrawal of the special inflation allowance) means that it will be more difficult to respond quickly and flexibly to new opportunities as they arise, or to manage phased introductions of new products - involving proper evaluation and comparison with other offerings - before taking decisions to cancel hard-copy equivalents gradually, starting with material considered to be of marginal value.

The combined effects of budget cuts for 1992-93 and 1993-94 have been to reduce printed journal subscriptions by some 300 titles, bringing total hard-copy holdings to under 850 titles; at the same time, introduction of the ADONIS full-text CD-ROM system last year has added more than 500 titles in electronic form to on-site resources. The migration from print to electronic has been most dramatic in the area of abstracts and indexes: in 1992-93 the breakdown of expenditure was almost equally divided between printed, online and CD-ROM sources (i.e. printed products accounting for approximately one-third of the total spend) but for 1993-94, after cancellation of a further ten subscriptions, the balance has shifted significantly towards CDROMs (more than 50 per cent) and away from print (about 15 per cent) with the online share remaining relatively stable. The proportionate spend on book purchases has been progressively reduced over the years, reflecting general price swings from books to serials, and the changes in demand during this period. Policy here is to target expenditure closely on material to support undergraduate needs as expressed in recommendations received via reading lists. Implementation of this strategy relies on ongoing systematic evaluation of material against current academic priorities, which is in turn dependent on effective liaison and consultation with academic staff by a team of information specialists. As foreshadowed above, a continuous programme of weeding/deselection now runs in parallel with the selection of new additions to stock; a major exercise conducted this year has resulted in cancellation of about 600 standingorder subscriptions, judged to be no longer relevant to current needs.

The provision of rapid access to a comprehensive range of (remote) document supply services has been an integral part of the Aston LIS strategy from the outset, and recent years have seen a significant upsurge in interlibrary loan demand, especially following the introduction of extensive self-service bibliographic database search facilities (and also reflecting the tendency for undergraduate reading to focus more than before on journal articles in the context of project work). Budget constraints now necessitate tighter control of expenditure in this area, and we aim to achieve this not by imposing charges - as many other university libraries have done - but by introducing new procedures requiring academic departments to take more active responsibility for assessing needs and authorizing requests. User fees for interlibrary loans would be at odds with the access model, implying that document supply services from other sources were an optional extra, rather than an integral part of our overall strategy.

\section{Trading Company Model and Service Level Agreements}

Coincident with this period of budget adjustments, the University has begun to move towards a new way of viewing its financial situation, with the adoption of a trading company model (TCM). TCM acknowledges that the institution's income stream is almost entirely determined by the teaching and research activities of its academic departments, and their earnings can be identified explicitly under the more transparent funding models now used by the Higher 
Education Funding Council for England. The model requires both income and expenditure to be set out for each academic department to establish whether it has a balanced budget. This in turn requires the "non-earning" departments, such as LIS and other central support services, to identify the costs of service provision to each client department so that these may be shown as expenditure on the balance sheet.

Although LIS had been moving towards the development of a comprehensive service/activity model to bring performance indicators and service costings together, this work was not completed when TCM was introduced. Over the last two years there has been rapid progress in this direction, to assist with the apportionment of costs to academic departments. The need to accommodate both function-based and subject-based costings in management information systems has been agreed, recognizing the desirability of obtaining a broader picture of total information resource provision incorporating monograph and serial purchases, electronic sources and interlibrary loans for each subject area. This model then had to be extended to map subjects to departments taking account of the interdisciplinary nature of many teaching and research programmes, including (for example) the fact that chemistry journals are used both by the Department of Chemical Engineering and Applied Chemistry and the Department of Pharmaceutical and Biological Sciences. Matrix management arrangements were already in operation in LIS to reflect the multifunctional roles of most staff; this principle is now being applied to the system of devolved cost centres and budgets. Figure 1 is a reproduction of illustration in an internal document setting out the relationships between functional and customer/departmental financial management responsibilities.

\begin{tabular}{|c|c|c|c|c|c|c|c|}
\hline & \multicolumn{4}{|c|}{ Acquisitions } & \multirow{2}{*}{$\begin{array}{l}\text { Cataloguing, } \\
\text { Classification } \\
\text { and Indexing }\end{array}$} & \multirow{2}{*}{$\begin{array}{l}\text { Inter- } \\
\text { Library } \\
\text { Loans }\end{array}$} & \multirow[b]{2}{*}{$\begin{array}{l}\text { Budget } \\
\text { Holder }\end{array}$} \\
\hline & Books & $\begin{array}{c}\text { Standing } \\
\text { Orders }\end{array}$ & Serials & $\begin{array}{l}\text { Electronic } \\
\text { Sources }\end{array}$ & & & \\
\hline Chem Eng & $£$ & $£$ & $£$ & $£$ & $£$ & $£$ & \multirow{5}{*}{$\begin{array}{c}\text { Info Spec } \\
\text { Engineering }\end{array}$} \\
\hline Civil Eng & $£$ & $£$ & $£$ & $£$ & $£$ & $£$ & \\
\hline Comp Sci & $£$ & $£$ & $£$ & $£$ & $£$ & $£$ & \\
\hline Elec Eng & $£$ & $£$ & $£$ & $£$ & $£$ & $£$ & \\
\hline Mech Eng & $£$ & $£$ & $£$ & $£$ & $£$ & $£$ & \\
\hline Pharm Sci & $£$ & $£$ & $£$ & $£$ & $£$ & $£$ & \multirow{2}{*}{$\begin{array}{c}\text { Info Spec } \\
\text { Life Sciences }\end{array}$} \\
\hline Vision Sci & $£$ & $£$ & $£$ & $£$ & $£$ & $£$ & \\
\hline $\begin{array}{l}\text { Business } \\
\text { School }\end{array}$ & $\begin{array}{l}£ \\
£ \\
£\end{array}$ & $\begin{array}{l}£ \\
£ \\
£\end{array}$ & $\begin{array}{l}£ \\
£ \\
£\end{array}$ & $\begin{array}{l}£ \\
£ \\
£\end{array}$ & $\begin{array}{l}£ \\
£ \\
£\end{array}$ & $\begin{array}{l}£ \\
£ \\
£\end{array}$ & $\begin{array}{c}\text { Info Spec } \\
\text { Bus and Man } \\
\text { Bus and Law } \\
\text { ML/Int Bus }\end{array}$ \\
\hline $\begin{array}{c}\text { Modern } \\
\text { Languages }\end{array}$ & $£$ & $£$ & $£$ & $£$ & $£$ & $£$ & $\begin{array}{l}\text { Info Spec } \\
\text { ML/Int Bus }\end{array}$ \\
\hline $\begin{array}{c}\text { Cost Centre } \\
\text { Manager }\end{array}$ & \multicolumn{4}{|c|}{$\begin{array}{l}\text { Acquisitions } \\
\text { Manager }\end{array}$} & $\begin{array}{l}\text { Bib Recs } \\
\text { Manager }\end{array}$ & $\begin{array}{l}\text { Doc Supply } \\
\text { Manager }\end{array}$ & \\
\hline
\end{tabular}

Figure 1. LIS Information Resources Cost Centre/Budget Matrix

There was also a need to decide on the basis for allocating costs for different services, and here a distinction was drawn between "standard" services, offered to prime users (students and staff) on the assumption of equal opportunities for access, and "tailored" services, designed - in consultation with academic departments - to meet specific needs identified for particular teaching and research programmes.

A breakdown of the services assigned to each category is shown in Table 1. 
Table 1. LIS Allocation of Services to Categories

\begin{tabular}{|l|l|}
\hline Standard services & Tailored services \\
\hline Study facilities & Collection development and management \\
General reference collection & - books \\
Online public access catalogue (OPAC) & - standing orders \\
Access to microcomputing facilities & - journals \\
General/basic publicity material & - electronic sources \\
Counter services & - other materials (e.g. dossiers, microforms, videos) \\
Short loan collection & Interlibrary loans \\
Photocopying facilities & Special leaflets and instructional handouts \\
Public information points & In-depth enquiries \\
Induction talks and tours & Information skills programmes \\
Study skills programme & Mediated online searches \\
Exhibition facilities/new books display & Current awareness/SDI services \\
\hline
\end{tabular}

Costs of standard services have been apportioned on the basis of student numbers, in the belief that to take account of the actual usage/participation rates of general enquiry services, induction tours, loan facilities, etc., would undermine the principle of promoting optimum take-up of services which are not differentiated in their conception or management. In contrast, the costs of tailored services (e.g. book and journal acquisitions, interlibrary loans, information skills programmes, online searches - including staff costs) have been allocated according to actual or perceived usage, drawing on expressed demand from academic departments, use data from automated systems and the informed judgement of LIS information specialists. This has involved a title-by-title consultation exercise with academic staff to agree the attribution of standing orders and serials subscriptions to one or more departments.

At this stage TCM is an apportionment model rather than a funding mechanism, in that the budget is still determined centrally, as opposed to being the sum total of the amounts individual departments elect to spend on LIS. However, with TCM, academic heads have been more closely involved in deciding the overall budget for LIS, and the apportionment exercise has helped them to understand better the likely impact of budget adjustments at both institutional and departmental level. This has encouraged the development of service level agreements with each department, acknowledging the scope for providing a different mix of products and services according to the varying requirements of teaching and research programmes (recognizing, for instance, that the proportionate spend on books, journals and electronic sources will not be uniform across all departments/subject areas). This approach also provides a framework and mechanism to monitor activities and performance throughout the year, so that if the need to exceed a departmental allocation of interlibrary loan requests is identified, a midsession budget adjustment can be negotiated, either by virement between expense heads or transferring funds from the department to LIS. This sort of planned and negotiated budget adjustment at departmental level is surely more appropriate than charging individuals for interlibrary loan requests on an ad hoc basis.

\section{The University Library of the Future}

Returning to the starting-point of $1985-86$ - the model of the specialized, industrial library and information service - comparison in 1993 of Aston LIS with a leading exponent in the field shows that this still represents the closest match to the type of service to be provided in the 
latter part of the 1990s. The networked information services of Glaxo Group Research (GGR) are similarly characterized by automation of library housekeeping activities, a judicious mix of stand-alone and networked CD-ROM services, extensive end-user online searching, and increasing predominance of electronic services over printed sources.

In addition, GGR provision already encompasses features envisaged but not yet universally implemented at Aston, such as electronic current awareness services, including SDI via e-mail and online browsing of table-of-contents data; local software enabling processing of online search results with automatic flagging of journal titles held on-site; and full automation of interlibrary loans - no manual requests are accepted from users at GGR. Significantly, GGR information services staff "have recently sought a working mandate from the business that, wherever practical, information services should be available and delivered electronically; and, that if a service is available electronically, we should not provide access to it via a manual or printed source", and a key question for the future - acknowledging the perceived value of serendipity in the research process - is "whether we can mimic technically the browsability and portability of printed services". Industrial scientists apparently share with their academic counterparts a reluctance to sacrifice access to a core collection of journals which they can handle conveniently and instinctively [12].

\section{ADONIS and After}

The experience of implementing the ADONIS full-text document delivery system during 1992-93 has brought into sharper focus some of the key issues to be addressed in realizing the vision of the networked electronic library [13]. One of the key attractions of the system is the prospect of providing immediate access to some 500 journal titles, of which only 70 or so were represented in current journal subscriptions, thus offering the possibility of a reduction in interlibrary loan costs; it was also hoped that by cancelling the hard-copy equivalents it would be possible to achieve an overall saving, even when taking into account the royalty charge on each article printed. The system is undergoing a full working trial for one year, including a technical evaluation, a survey of customer reactions and cost/benefit analysis. Although introduced in October 1992, the trial proper only really began in early 1993 as the hardcopy cancellations started to take effect.

Initial customer reactions indicated that the omission of contents pages from the database, difficulties in browsing articles on screen and practical problems in using the mouse and cursor combination to navigate through the system were perceived as significant drawbacks - as was the fact that the service was not networked, but installed on a stand-alone workstation in the library building. To remedy this situation the LIS Computer Officer has developed software to manipulate and network the ADONIS indexes and provide a de facto table-of-contents service to the desktops of users. In addition, features have been added enabling users to tag articles required and transmit their requests automatically to LIS, which can then be batch processed and printed each morning, for rapid supply through the internal post [14].

Initial steps in conducting cost/benefit analysis have confirmed the need to obtain a more detailed and comprehensive picture of the total costs associated with different modes of service delivery. The life cycle costs of our journals are now being investigated, to establish what the true savings are when a printed journal is cancelled, taking into account all the costs incurred from ordering and receipt, through cataloguing and processing, to binding and storage, drawing on the work done by the British Library in its review of acquisition and retention policies [15]. In assessing the costs of electronic provision, it is essential to take into account not only the 
subscription and royalty charges, but also both capital and recurrent expenditure involved in installing, maintaining and upgrading/replacing hardware and software (covering PCs, servers, laser printers, jukeboxes, etc.) as well as the cost of additions and changes to catalogue records for journals held in electronic form. Evaluations of printed versus electronic and on-site versus remote supply are becoming more complex with the wider options for networked document delivery becoming available (potentially direct to end users) following the introduction of new services such as those provided by CARL, Faxon, OCLC and RLG, with their different charging structures and payment methods - which also necessitate decisions about acquiring material on a permanent or temporary basis, for institutional or individual use/retention [16].

\section{The Management Challenge}

The above account indicates some of the factors determining the optimum mix of information resources for a university library; others have confirmed the complexity of the issues, and identified the need for a series of studies, notably to clarify the technical and financial feasibility of electronic document storage and delivery systems [17].

Undoubtedly, funding and pricing issues will continue to dominate the debate over the next decade as they have in the past: high inflation, currency fluctuations and the multiplicity of charging structures (pay-as-you-go, flat fees based on user population, block-of use purchases - with or without academic discounts) make it difficult to predict costs, even if a secure resource base were guaranteed; new payment mechanisms, facilitating direct access for end users, must be approached with caution, lest they inadvertently undermine the access philosophy, and cause a loss of commitment to ensuring the most cost-effective provision for the institution as a whole [18]. Fortunately, these issues - including the vexed question of copyright - are currently the subject of discussion at national level in the UK, notably by the Higher Education Funding Councils Libraries Review and the British Library Working Party on Electronic Publishing, and representatives of both the LIS and publishing communities are contributing to the debate.

The library of the future will be defined less in terms of the quality of its collections (holdings) and more in terms of quality of access. Quality of access is dependent on the technical infrastructure and navigational tools but, above all, on the expertise of staff, whose ability to identify needs, exercise judgement in the allocation of resources and help users to find and exploit information will be critical. Information skills programmes are being extended in depth and breadth; electronic sources require more sophisticated search tools and techniques than printed materials, with the use of truncation and Boolean operators; users also need to know how to get access to networks, and not just how to retrieve information, but how to manage it (by downloading, storing, organizing and manipulating data) when they have done so. Information specialists are moving from mediation to management: the role has already changed from that of searcher/intermediary to adviser, instructor and facilitator; but now it is being extended again as the information specialist becomes the local operational manager responsible for the internal delivery of the relevant electronic services - a responsibility likely to include negotiations with suppliers about terms and conditions; oversight of installation and testing of new systems; preparation of user documentation; training of LIS staff, as well as end users; and continuing consultation and liaison with customers in order to monitor and evaluate provision.

The blurring of roles and boundaries between libraries and computing centres is another complicating factor. It is inappropriate to view this as a power struggle; we need to recognize the 
specialist expertise needed - on the one hand, how to search for, retrieve and organize information; on the other, how to connect via networks, develop gateways and user interfaces and consider how best to form effective partnerships in planning and delivering services for customers. The question of whether the library/information services and computing/information systems functions ought to be structurally merged or separate is a matter for institutions to determine in accordance with local circumstances and preferences; however, it is absolutely crucial that interdependencies are properly acknowledged and synergy through teamwork is achieved. At Aston, the two departments are separate with no plans for structural convergence but they work closely together, with frequent informal contact, at both strategic and operational level. LIS has its own computer officer (a post created by reducing staff resource elsewhere) and is heavily dependent on the postholder's expertise and energy in supporting day-to-day operations and finding creative solutions to problems; it is hard to imagine how an IT-based service could function without dedicated on-site support of this type.

\section{Critical Success Factors}

In 1991, as part of Aston University's total quality management initiative, an exercise was carried out to identify "critical success factors", defined here as a set of issues which taken together are necessary and sufficient to accomplish the LIS mission [19]. This list will serve here as a summary of the factors judged to be of central importance in moving from the holdings to the access model:

- Strategic framework - an articulated strategy, represented by a shared vision and mission, agreed strategic and operational plans and priorities.

- Staff of the right calibre - at all levels, trained and developed through continuing programmes, to enable them to achieve their full potential.

- Focus on the customer - an open and inviting environment, quick flexible responses, and services targeted to meet the needs of all user groups.

- Culture encouraging innovation and ownership, allowing devolved responsibility identified as an achievement/people (support) model [20].

- Effective communication, internally and externally - at all levels.

- Effective IT infrastructure, with adequate technical support.

- Secure resource base to match customer demands.

- Comprehensive management information systems.

\section{References}

1. University Grants Committee, Capital Provision for University Libraries: Report of a Working Party, HMSO, 1976 (Chairman: Professor Richard Atkinson).

2. Ford, G., "A Review of Relegation Practice", in Collection Development: Options for Effective Management, Taylor Graham, London, 1988, pp. 71-87.

3. Mann, P., “University Expansion, Library Contraction”, Library Association Record, Vol. 92 No. 2, 1990, pp. 115-7.

4. Peasgood, A., "Towards Demand-led Book Acquisitions? Experiences in the University of Sussex Library", Journal of Librarianship, Vol. 18 No. 4, 1986, pp. 242-56. 
5. Department of Education and Science/Office of Arts and Libraries, The Future Development of Libraries \& Information Services 2: Working together within a National Framework, Library Information Series No. 12, HMSO, 1982, p. 25.

6. Harley, A.J., "Towards the Virtual Library", in The Nationwide Provision and Use of Information: Aslib/IIS/LA Joint Conference Proceedings, Library Association, London, 1980, pp. 163-6.

7. East, H., Balancing the Books: Resourcing Electronic Information Services in Academic and Public Libraries, CCIS Policy Paper No. 3, British Library R\&D Report 6057, Centre for Communication and Information Studies, Polytechnic of Central London, 1991.

8. Brindley, L.J., "Case Study: Aston University", in The Electronic Campus: An Information Strategy, Library and Information Research Report 73, British Library, 1989, pp. 91-7.

9. Abbott, C., "Using Excel at Aston University Library \& Information Services: The Application of Spreadsheets to Library Stock Management", Program, Vol. 24 No. 3, 1990, pp. 269-79.

10. Cusworth, E., "Networking on a University Campus and its Effect on Library Services", Libri, Vol. 41 No. 4, 1991, pp. 248-61.

11. Desktop Delivery (1991) and The Electronic Library (1992) - guides to networked library services and networked electronic information resources; Anybody's Networking Book (1993) - a simple guide to networked services at Aston, including what they are, how to get connected and where to get help; ABI/Inform, Bibliographie Nationale Française, Compendex on CD-ROM, Datastream, PsycLit, Textline and others - leaflets on specific databases.

12. Swain, S., "Networked Information Services in Support of Pharmaceutical Research", in Computers in Libraries International 93: Proceedings of the Seventh Annual Computers in Libraries International Conference held in London in February 1993, Meckler, 1993, pp. 2734.

13. Smith, N., "ADONIS at Aston: From 'Just in Case' to 'Just in Time'", in Taming the Electronic Jungle - Electronic Information: The Collection of Management Issues, National Acquisitions Group and United Kingdom Serials Group, Leeds, 1993, pp. 96-105.

14. Craft, E.J., "Distributed ADONIS Indexing: The Aston University LIS Solution", ADONIS News, Vol. 4 No. 1, 1993, pp. 1-3.

15. Stephens, A., "The Application of Life Cycle Costing in Libraries", British Journal of Academic Librarianship, Vol. 3 No. 2, 1989, pp. 82-8.

16. Leach, R.G. and Tribble, J.E., "Electronic Document Delivery: New Options for Libraries", Journal of Academic Librarianship, Vol. 18 No. 6, 1993, pp. 359-64.

17. Baker, D., "Access versus Holdings Policy with Special Reference to the University of East Anglia", Interlending \& Document Supply, Vol. 20 No. 4, 1992, pp. 131-7.

18. Martin, M.J., "Academic Libraries as Information Consumers: Implications for Policy Making", Journal of Academic Librarianship, Vol. 17 No. 2, 1991, pp. 93-8.

19. Hardaker, M. and Ward, B.K., "How to Make a Team Work", Harvard Business Review, Vol. 65 No. 6, 1987, pp. 112-7.

20. Harrison, R. and Stokes, H. Diagnosing Organization Culture: An Instrument, Roffey Park Institute, Horsham, 1986 (1990).

Sheila M. Corrall is Director of Library \& Information Services at Aston University, Birmingham, UK. 